\title{
KINETICS OF THE CLEAVAGE OF THE
}

\section{LACTONE RINGS OF NATURAL COUMARINS}

\author{
Yu. E. Orlov and R. V. Piskareva
}

UDC 547.582

The cleavage of the lactone ring of coumarins in the presence of bases is one of the main and specific reactions in the chemistry of natural coumarins [1-5]. Using a polarographic method [5], we have studied the influence of the chemical structure and the nature of the solvent and of the base on the kinetics of the cleavage of coumarins.

In view of the occurrence (in addition to the main reaction) of parasitic photochemical reactions, all the measurements were performed in a darkened thermostated cell $\left(25^{\circ} \mathrm{C}\right)$. It was found that the reaction takes place according to a second-order law. The rate constant falls with a rise in the concentration of organic solvent in water (values of the constant for coumarin expressed in liter $/ \mathrm{mole} \cdot \mathrm{sec}$; water -0.35 ; $25 \%$ methanol $-0.22 ; 50 \%$ methanol $-0.07 ; 70 \%$ methanol -0.02 ).

A similar fall in the constants was observed for ethanol-water, propanol-water, isopropanol-water, and dimethyl-formamide-water media.

In pure organic solvents the lactone ring of coumarins undergoes no cleavage whatever, as has been confirmed polarographically and chromatographically. This shows the participation of water in the cleavage of the lactone ring of a coumarin in the presence of alkali.

We also studied the influence of the nature of the base (lithium, ammonium, sodium, potassium, and tetraethylammonium hydroxides). In none of the media mentioned above does ammonium hydroxide cleave the lactone ring of a coumarin. The effects of the other hydroxides in aqueous alcoholic media are practically identical (similar values of the constants), with the exception of an aqueous medium (values of the constants for coumarin in water expressed in liter/mole. sec: $\mathrm{LiOH}-0.33, \mathrm{NaOH}-0.35, \mathrm{KOH}-0.39$ ).

With a rise in the temperature, the constant rises linearly, and the activation energy determined from this relationship is $11.5 \mathrm{kcal} / \mathrm{mole}$.

In the case of hydroxycoumarins, apparently, the main reaction is chain autooxidation [6] of the phenolic hydroxyl, and therefore the oxidation products do not permit the recording of a characteristic fall in the height of the polarographic wave of the coumarin. The introduction of donor substituents opposes the cleavage of the lactone ring, just as in the polarographic reduction of the 3,4-bond of the $\alpha$-pyrone ring of a coumarin [7]. For herniarin in 50\% methanol, $K=0.069$, and for coumarin $K=0.045$. The introduction of a furan ring into the coumarin system decreases the rate constant of the cleavage of the lactone ring by a factor of 2-3 (bergapten, psoralen, xanthotoxin, etc.).

\section{TERATURE CITED}

1. G. A. Kuznetsova, Natural Coumarins and Furocoumarins [in Russian], Moscow (1967).

2. K. Bowden, M. J. Hansen, and G. R. Taylor, J. Chem. Soc., B, 174 (1968).

3. B. C. Lippold and E. R. Garrett, J. Pharm. Sci., 60, No. 7, 1019 (1971).

4. E. R. Garrett, B. C. Lippold, and J. B. Mielck, J. Pharm. Sci., 60, No. 3, 396 (1971).

5. Yu. E. Orlov and A. P. Prokopenko, Khim. Pri rodn. Soedin., 216 (1969).

6. P. P. Semenov, Chain Reactions [in Russian], Leningrad (1934).

7. Yu. E. Orlor and A. P. Prokopenko, Zh. Obshch. Khim., C11, 1159 (1970).

Academician 1. P. Pavlov Ryazan' Medical Institute. Translated from Khimiya Pri rodnykh Soedinenii, No. 1, p. 87, January-February, 1974. Original article submitted July 13, 1973. 